\title{
DIAGNÓSTICO SEROLÓGICO (ROSA DE BENGALA) Y MOLECULAR (PCR) DE BRUCELOSIS EN HUMANO
}

\author{
${ }^{\bullet}$ Orly Cevallos Falquez ${ }^{1}$, Mercedes Carranza Patiñoㅇ, Silvia Saucedo Aguiar ${ }^{1,2}$, Diego Romero Garaicoa ${ }^{1}$, \\ Luís Ramos Gavilanes ${ }^{1,3}$, Ximena Reyes Chancay ${ }^{1}$, Ketty Cobeña Rosado ${ }^{4}$, Aldelmo Rodríguez Grefa ${ }^{5}$, \\ Jonathan Mariscal Álvarez ${ }^{5}$, Camilo Mestanza Uquillas ${ }^{1}$, Maria Lorena Cadme ${ }^{1}$, Ariel Escobar Troya ${ }^{1}$, \\ Jaime Vera Chang ${ }^{1}$ y Fabricio Canchignia Martínez \\ ${ }^{1}$ Unidad de Investigación Científica y Tecnológica, Universidad Técnica Estatal de Quevedo, $\mathrm{km} 7$ vía \\ Quevedo - El Empalme, C.P. 73. Mocache,Los Ríos, Ecuador. orlycevallos@hotmail.com \\ ${ }^{2}$ Facultad de Ciencias Agrarias, Universidad Técnica Estatal de Quevedo, $\mathrm{km} 1$ 1/2 vía a Santo Domingo \\ de los Tsáchilas, C. P. 73. Quevedo, Los Ríos, Ecuador. \\ ${ }^{3}$ Facultad de Ciencias Ambientales, Universidad Técnica Estatal de Quevedo, $\mathrm{km} 1$ 1/2 vía a Santo Domingo \\ de los Tsáchilas, C. P. 73. Quevedo, Los Ríos, Ecuador. \\ ${ }^{4}$ Facultad de Ciencias Pecuarias, Universidad Técnica Estatal de Quevedo, km 7 vía a El Empalme \\ Mocache, Los Ríos, Ecuador \\ ${ }^{5}$ Unidad de Estudios a Distancias, Universidad Técnica Estatal de Quevedo, $k m 11 / 2$ vía a Santo Domingo \\ de los Tsáchilas, C. P. 73. Quevedo, Los Ríos, Ecuador.
}

\begin{abstract}
RESUMEN
E l objetivo de esta investigación fue: Determinar y comparar la presencia de Brucelosis del personal que labora en los camales de los cantones, Buena Fé, Quevedo, El Empalme y Pichincha, utilizando la prueba serológica Rosa de Bengala (RB) y la técnica molecular (PCR). Se utilizó como fuente de ADN y anticuerpos sangre periférica. De un total de 115 muestras de sangre recolectadas al personal que labora en los camales como faenadores y operadores, 54 (47\%) y 15 (13\%) fueron positivas con RB y PCR respectivamente, dando $61(53 \%)$ y $100(87 \%)$ negativas para las dos pruebas correspondientemente. El promedio de casos positivos para las tres poblaciones excepto Pichincha por PCR fue de $3.4 \%$ y para RB $39.4 \%$. Se toma atención con el cantón Pichincha debido a que $19(70.3 \%)$ de las muestras salieron positivas con RB de las cuales $12(44.4 \%)$ al ser analizadas con PCR fueron negativas, teniendo una correlación de $52.6 \%$, lo que indica una alta incidencia de la enfermedad. Mientras tanto que de las 8 muestras negativas con RB, 2 fueron positivas con PCR dando una correlación entre negativos del 75\%. Las muestras positivas amplificaron un fragmento de $725 \mathrm{pb}$. Con este trabajo se sugiere que la técnica de PCR es una herramienta altamente eficiente y muy útil para el diagnóstico de la brucelosis en humanos.
\end{abstract}

Palabras claves: Brucellas, serológica, sangre periférica, Ecuador.
Abstract

$\mathrm{T}$ The objective of this research was: To determine the presence of brucellosis in the personnel working in the slaughterhouses of the cantons, Buena Fe, Quevedo, El Empalme and Pichincha, the serological test using Rose Bengal (RB) and molecular techniques ( PCR). Was used as a source of peripheral blood DNA and antibodies. Of a total of 115 blood samples collected at staff working in the slaughterhouses and slaughterers and operators, $54(47 \%)$ and $15(13 \%)$ were PCR positive and $\mathrm{RB}$ respectively, giving 61 (53\%) and 100 (87\%) negative for both tests accordingly. The average number of positive cases for the three populations except $\mathrm{Pi}$ chincha by PCR was $3.4 \%$ and $39.4 \%$ RB. It takes care with the Pichincha Canton because 19 (70.3\%) of samples were positive with RB of which 12 (44.4\%) when analyzed with PCR were negative, and showed a $52.6 \%$ , indicating a high incidence of the disease. As long as the negative sample RB 8, 2 were PCR positive giving a correlation between negative $75 \%$. The positive samples amplified a fragment of $725 \mathrm{pb}$. This work suggests that PCR is a highly efficient tool and very useful for diagnosis of brucellosis in humans.

Key words: Brucella, serology, peripheral blood, Ecuador.

\section{INTRODUCCIÓN}

$\mathrm{L}$ a brucelosis es una de las zoonosis (antropozoonosis) de mayor difusión en el mundo en seres humanos y animales domesticados, esta infección es causada por microorganismos del género Brucella, generalmente transmitida al hombre por animales domésticos. La enfermedad se caracteriza por fiebre, sudoración, debilidad y malestar general, a menudo sin signos de localización (Kaye y Petersdo, 1989; Romero et al., 1995a).

Recibido: Octubre, 2009. Aceptado: Enero, 2010.

Publicado como ARTícULO en Ciencia y Tecnología 3(1): 27-32. 2010
La zoonosis está constituida esencialmente por las diferentes especies de bacterias que afectan al ganado bovino (B. abortus), caprino y ovino (B. melitensis y ovis), cerdo (B. suis) y B. canis en el perro (Kaye y Petersdo, 1989).

Uno de los accesos por donde se adquiere la enfermedad es por el contacto directo por vía cutánea o por aerosoles procedente de sangre, placenta, fetos o secreciones uterinas o por el consumo de productos crudos o mal cocidos (leche, productos lácteos y cárnicos 
incluyendo embutidos) animales infectados. Se considera una enfermedad profesional en ganaderos, veterinarios y otras profesiones expuestas. Por afectar la salud pública y la economía ganadera generando pérdidas económicas de importancia, la brucelosis tiene una gran repercusión mundial (Gotuzzo et al., 1989).

El diagnóstico tradicional de brucelosis se basa en la sospecha clínica de la enfermedad, que aparentemente es confirmada por demostración de Brucella en el organismo por la reacción antígeno-anticuerpo a partir de la sangre. Las pruebas serológicas son métodos rápidos, accesibles y de un costo aceptable. La dificultad es su variabilidad de interpretación, dependiendo si el individuo se encuentra en áreas endémicas o no (Martín, 1992; Salmerón, 1992), las áreas urbanas o rurales y de la elección de la titulación a partir de la cual se considera como positiva (Salmerón, 1992).

En el Ecuador se utilizan muy poco estas pruebas para el diagnóstico de brucelosis en humanos, porque esta enfermedad se la confunde con otras que presentan síntomas muy similares. El diagnóstico serológico de la brucelosis por Elisa está considerada útil y rápida de screenning.

Actualmente la microbiología molecular ha entrado en el diagnóstico de esta infección. La literatura referente a PCR y Brucella en los diez últimos años presenta abundantes trabajo. La características de todos ellos es la sensibilidad y especificidad que muestran las técnicas moleculares para la detección de Brucella en diferentes muestras (sangres, médula, leche, orina, etc.). La PCR toma un protagonismo para el diagnóstico rápido y eficiente, dejando el aislamiento para otros trabajos especializados. Con el uso de estas técnicas se acorta el tiempo necesario para el diagnóstico, aportando además información útil para definir el estudio evolutivo o forma clínica de la enfermedad y el tratamiento más adecuado.

La reacción en cadena de la polimerasa (PCR) puede ser aplicada en el Ecuador como una prueba confirmatoria, para el diagnóstico de esta enfermedad. Los resultados de este trabajo establecen y consolidan la presencia de Brucelosis del personal que labora en los camales de los cantones de Buena Fé, Quevedo, El Empalme y Pichincha, utilizando especialmente la técnica de Reacción en Cadena de la Polimerasa.

\section{Materiales y Métodos}

\section{Recolección de muestras y pruebas serológicas}

$\mathrm{P}$ ara la implementación de la técnica de la PCR y Rosa Bengala, se tomaron al azar 115 muestras de sangre humana, a partir de la vena radial, cubital y mediana del brazo, de los cuales se extrajeron $5 \mathrm{~mL}$ de san- gre con anticoagulante. La toma de muestra se la realizó en cuatro camales ubicados en los cantones de Buena Fe; Quevedo (Prov. Los Ríos); El Empalme (Prov. Guayas) y Pichincha (Prov. de Manabí).

\section{Extracción de ADN}

\section{Protocolo de lisis de eritrocitos a partir de sangre}

Se utilizó el método de Leal-Klevezas et al. (1995 modificado), que se basó en: tomar $400 \mu \mathrm{L}$ de la muestra y microcentrifugada a $7000 \mathrm{rpm}$ por $3 \mathrm{~min}$. El sobrenadante fue resuspendido en $1 \mathrm{~mL}$ de solución de lisis de eritrocitos (155 mMNH4CL, $10 \mathrm{mMNaHCO}$, $100 \mathrm{Mm}$ disodium EDTA pH 7.4). Se mezcló y se microcentrifugó a $7000 \mathrm{rpm}$ por $3 \mathrm{~min}$. El tratamiento con solución de lisis de eritrocitos se repitió una vez más. El ADN templete se obtuvo a partir de los leucocitos como sigue: $400 \mu \mathrm{L}$ de solución de lisis ( $2 \%$ de Triton $\mathrm{x}-100$, $1 \%$ de SDS, $100 \mathrm{mM}$ de $\mathrm{NaCl}, 10 \mathrm{mM}$ Tris-HCl, $\mathrm{pH}$ 8) y $10 \mu \mathrm{L}$ de proteinasa $\mathrm{K}(10 \mathrm{mg} \mathrm{mL})$ se le añadió a las muestras. El contenido se mezcló con el uso del vortex y se incubó por $\left(40 \mathrm{~min}\right.$ a $\left.50^{\circ} \mathrm{C}\right)$. Luego se añadió 400 $\mu \mathrm{L}$ de fenol saturado (contenido de fenol líquido a $0.1 \%$, 8 hidroxiquinolina, saturado y estabilizado con $100 \mathrm{mM}$ Tris-Hcl (pH 8) y $0.2 \% 2$ mercaptoetanol, se vortezó y a continuación se microcentrifugó a $13000 \mathrm{rpm}$ por 5 min. La capa acuosa se transfirió a otro tubo y se le agregó un volumen igual de alcohol isoamil-cloroformo (24:1), el tubo se mezcló a fondo y se microcentrifugó a $10000 \mathrm{rpm}$ por $5 \mathrm{~min}$. El sobrenadante se transfirió a otro tubo y se le agregó $200 \mu \mathrm{l}$ de acetato de amonio 7.5 M y se vortezó. Luego se colocó en hielo por $10 \mathrm{~min}$, después se microcentrifugó a $10000 \mathrm{rpm}$ por 5 min y el contenido acuoso se transfirió a otro tubo. Dos volúmenes de etanol al $95 \%$ se añadió, se mezcló y el tubo fue almacenado a $-20^{\circ} \mathrm{C}$ por $30 \mathrm{~min}$. Se recuperó el ADN por microcentrifugación a $10000 \mathrm{rpm}$ por $5 \mathrm{~min}$. El ADN se lavó con etanol al 70\%, secado y resuspendido en $20 \mu \mathrm{L}$ de TE buffer $(10 \mathrm{mM}$ tris-HCL $\mathrm{pH} 8$, y $1 \mathrm{mM}$ Disodiun EDTA). La concentración del ADN fue determinada por medición DOA260 y las extracciones fueron almacenadas a $-20^{\circ} \mathrm{C}$ hasta su proceso de la PCR. Se incluyó siempre un control negativo de la extracción de ADN empleando agua destilada estéril en vez de sangre total y procesándola de la misma manera que las muestras de sangre total.

\section{Diseño de los oligonucletidos}

Para la detección específica de la Brucelosis con la técnica de la PCR, se emplearon iniciadores derivados de la secuencia $16 \mathrm{~S}$ ARNr que fueron publicados en el EMBL-X13695 del GenBank. 


\section{Amplificación del ADN por la PCR}

Se utilizó un volumen total de $50 \mu \mathrm{L}$, de 10 a $50 \mathrm{ng}$ de ADN, 1X Buffers, $1 \mathrm{U}$ de Taq polimerasa, $200 \mu \mathrm{M}$ de dNTPs, 25 pmol de cada oligonucleótido, $1.5 \mathrm{mM}$ de $\mathrm{MgCl} 2$ y $34.8 \mu \mathrm{L}$ de agua ultrapura estéril (Promega). El contenidos del mix sin el ADN templete como control negativo. La reacción fue programada en un termociclador (Cetus 9600, Perkín -Elmer). Las condiciones de amplificación se basaron en un programa de $94^{\circ} \mathrm{C}$ por $4 \mathrm{~min} \mathrm{y}, 40$ ciclos de $94^{\circ} \mathrm{C}$ por $1 \mathrm{~min}, 56^{\circ} \mathrm{C}$ por $80 \mathrm{seg}$ y $72^{\circ} \mathrm{C}$ por $80 \mathrm{seg}$ con una extensión final de $72^{\circ} \mathrm{C}$ por $10 \mathrm{~min}$.

\section{Electroforesis en gel de agarosa}

Los fragmentos amplificados fueron analizados mediante electroforesis en gel de agarosa al $2 \%$ en una solución de Buffer TAE, teñido con bromuro de etidio 2 $\mu \mathrm{L}$ mL (100 mg mL). Se depositó $15 \mu \mathrm{L}$ de cada muestra (amplicon) mezclado con $3 \mu \mathrm{L}$ de solución tamponada de carga (2.5 mL de azul de bromofenol al 1\%, $2.5 \mathrm{~g}$ de Ficoll, $1 \mathrm{~mL}$ de EDTA $0.5 \mathrm{M}$ al pH 8.0). Como marcador de peso molecular se empleó el de 100 pb de ADN (Gilco BRL). La migración fue a $70 \mathrm{~V}$ por una hora. Los productos de amplificación se visualizaron bajo luz UV. Las imágenes se capturaron con una cámara SonyPhotoshop $10 \mathrm{mp}$.

\section{Resultados}

$\mathrm{D}$ entro del marco de desarrollo y vinculación social de la UTEQ, dirige este trabajo al diagnóstico de brucelosis humana al personal que labora en los camales municipales de los cantones: Buena Fé, Quevedo, El Empalme y Pichincha; con el objetivo subsiguiente de evaluar la incidencia de la enfermedad en estos lugares y por ende realizar un estudio comparativo de la eficiencia de las técnicas de PCR versus la prueba serológica Rosa de Bengala.

\section{Extracción de ADN}

Se utilizó el protocolo de extracción de ADN descrito por Leal-Klevezas et al. (1995 modificado). La cantidad de ADN extraído obtenida se estimó entre 25 $\mu \mathrm{g} \mathrm{mL}$ en aproximadamente todas las muestras. La condición de pureza fue estimada en un promedio de 1.87 nm. Se utilizó este ADN como templado para realizar las pruebas de PCR.

\section{Análisis de PCR}

Se utilizó el juego de primer AB1-R2, los resultados de amplificación obtenidos son los visualizados en el gel cuyo tamaño de banda es de 725 pb. (Figura 1). Como se puede interpretar, la línea 2 indica muestra negativa, las líneas desde la 3 a la 7 son muestras positivas, las líneas $\mathrm{C}+\mathrm{y} \mathrm{C}$ - son los controles positivos y negativos respectivamente.

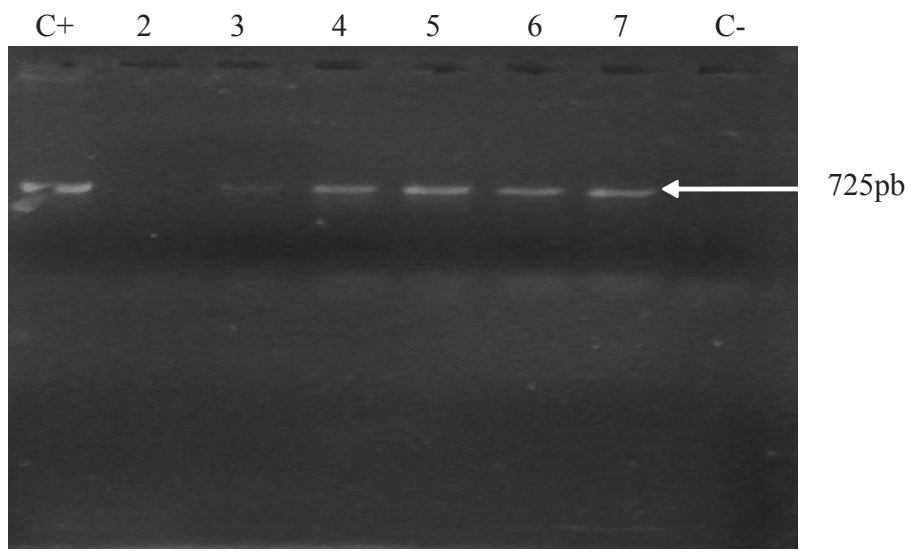

Figura 1. Resultados de la PCR con muestras de sangre de humano con los Oligonucleótidos AB1- R2

Estudio comparativo de inmunopruebas versus la PCR

De un total de 115 muestras 7 fueron mujeres
(6.1\%) y 108 fueron hombres (93.9\%) con edades promedios de entre 10 a 68 años. Los datos obtenidos en este trabajo demuestran un $47 \%$ positivo con la prueba Rosa de Bengala y 13\% para la técnica de PCR. 
Estudio epidemiológico en los camales Municipal de los cantones:

\section{Buena Fé, Provincia de Los Ríos}

En este lugar se analizaron a 29 individuos que fueron considerados con factores de contagio directo e indirecto, puesto que laboran como operarios y faenadores del área de sacrificio del matadero. Con la prueba de Rosa de Bengala, los resultados dieron 15 positivos (51.7\%) y 14 negativos (48.3\%).

$\mathrm{Al}$ analizar las mismas muestras con la técnica de PCR, los resultados fue de 1 positivo (3.4\%) y 28 negativos $(96.6 \%)$ con un índice de correlación del 100\% entre las dos técnicas (Cuadro 1).

Cuadro 1. Resultados con la prueba Rosa Bengala vs PCR en muestras de sangre de 29 individuos del personal que labora en el camal Municipal del cantón Buena Fé

\begin{tabular}{lcc}
\hline Pruebas & Positivos & Negativos \\
\hline PCR & 1 & 28 \\
Rosa de Bengala & 15 & 14 \\
\hline
\end{tabular}

\section{Quevedo, Provincia de Los Ríos}

Se analizaron 28 individuos utilizando el criterio anterior. Con la prueba de Rosa de Bengala, los resultados dieron 6 positivos $(21.4 \%)$ y 22 negativos $(78.6 \%)$.

Al analizar estas muestras con la técnica de PCR, los resultados fueron de 1 positivo (3.6\%) y 27 negativos (96.4\%) con un índice de correlación del 100\% entre las dos técnicas (Cuadro 2).

Cuadro 2. Resultados con la prueba Rosa Bengala vs PCR en muestras de sangre de 28 individuos del personal que labora en el camal Municipal del cantón Quevedo

\begin{tabular}{lcc}
\hline Pruebas & Positivos & Negativos \\
\hline PCR & 1 & 27 \\
Rosa de Bengala & 6 & 22 \\
\hline
\end{tabular}

\section{El Empalme, Provincia del Guayas}

Se analizaron 31 muestras demostrandose con la prueba de Rosa de Bengala, los resultados dieron 14 positivos $(45.2 \%)$ y 17 negativos $(54.8 \%)$.
Al analizar estas muestras con la técnica de PCR, los resultados fueron de 1 positivo (3.3\%) y 30 negativos $(96.7 \%)$ con un índice de correlación del 100\% entre las dos técnicas (Cuadro 3).

Cuadro 3. Resultados de los valores con la prueba Rosa Bengala vs PCR en muestras de sangre de 31 individuos del personal que labora en el camal Municipal del cantón El Empalme

\begin{tabular}{lcc}
\hline Pruebas & Positivos & Negativos \\
\hline PCR & 1 & 30 \\
Rosa de Bengala & 14 & 17 \\
\hline
\end{tabular}

Pichincha, Provincia de Manabí

En 27 muestras de sangre usando la prueba de Rosa de Bengala, los resultados dieron 19 positivos $(70.4 \%)$ y 8 negativos $(29.6 \%)$. Mientras que, con la técnica de PCR, los resultados fueron 12 positivos (44.4\%) y 15 negativos (55.5\%) (Cuadro 4).

Cuadro 4. Resultados de los valores con la prueba Rosa Bengala vs PCR en muestras de sangre de 27 individuos del personal que labora en el camal Municipal del cantón Pichincha

\begin{tabular}{lcc}
\hline Pruebas & Positivos & Negativos \\
\hline PCR & 12 & 15 \\
Rosa de Bengala & 19 & 8 \\
\hline
\end{tabular}

\section{Discusión}

$\mathrm{E}^{\mathrm{n}}$ el hombre, el comportamiento clínico de pacientes en zonas de una moderada incidencia de brucelosis, adversamente presentan elevadas seroprevalencias momentáneas con tendencia ascendente, es característico para los estados epizoóticos naturales y espontáneos de la enfermedad; es decir, aquellos en los que no existe control sobre las fuentes y vías de transmisión de la brucelosis (Romero et al., 1999). Esto nos ha llevado a ampliar las investigaciones, especialmente sobre el uso de las nuevas tecnologías para enfrentar los problemas sin resolver diagnósticos referentes a la brucelosis.

La PCR es una prueba con alta sensibilidad y especificidad, sin embargo un resultado negativo no excluye la presencia de la enfermedad (Morata et al., 1999; 2001a; 2001b). Por otro lado la PCR no provee información diferencial entre una enfermedad activa, 
porque la técnica no puede diferenciar entre ADN a partir de organismos vivos o muertos. A diferencia de las pruebas serológicas su interpretación no requiere conocer los antecedentes del enfermo y valorar las características clínicas presentes puesto que, al inicio de la enfermedad o en casos muy avanzados de la misma, la prueba da los resultados esperados, a diferencia de la prueba de la Rosa de Bengala cuando es negativa, debido a que los anticuerpos responsables de la seroaglutinación son fundamentalmente de la clase IgM, lo habitual es que vayan descendiendo en el transcurso de 3-6 meses, con o sin curación de la enfermedad.

Se ha demostrado que cuando la infección está establecida en forma endémica, prácticamente todos las personas tienen o han tenido contacto con el patógeno, por lo que existe respuesta inmunológica en personas portadores y no portadores de la bacteria.

Los resultados de este estudio muestran que la PCR es un método eficaz para identificar brucelosis en humano a partir de muestras de sangre periférica (Romero et al., 1999). Nuestro trabajo coinciden con los expuestos con (Rabab et al., 2000) a lo que es demostrado por la amplificación del segmento de ADN de $725 \mathrm{pb}$.

Los oligonucleótidos utilizados para la identificación resultaron aptos para identificar brucelosis en humano en todas las muestras en estudios. Han sido diversos los tipos de oligonucleótidos cebadores empleados, basados en secuencias de los genes $16 \mathrm{~S} \mathrm{ARNr}$ (Romero et al., 1995a, 1995b), omp2a (Leal-Klevezas et al., 1995), BCSP31 (Baily et al., 1992).

La prueba serológica de Rosa Bengala en muchos de los casos ha tenido una alta reacción cruzada con los anticuerpos a otra bacteria como E. coli; V. cólera, Y. enterólítica.

\section{Conclusiones}

El diagnóstico de la brucelosis es con frecuencia difícil de establecer. Esto no es sólo porque clínicamente, la enfermedad puede imitar cualquier enfermedad infecciosa y no infecciosa, sino también porque los métodos de diagnóstico establecidos no siempre son exitosos. En este estudio, hemos tratado de evaluar las técnicas de PCR en el diagnóstico de la brucelosis en comparación con las técnicas convencionales

En vista de las varias ventajas de la PCR a los métodos convencionales para el diagnóstico de la brucelosis, tales como la velocidad, seguridad, alta sensibilidad y especificidad, la técnica podría ser adecuada para el diagnóstico de laboratorio de brucelosis. Sin embargo, para la evaluación de las personas asintomáticas muy expuesta, la PCR podría considerarse complementaria a los métodos tradicionales y el seguimiento de la serología y/o los cultivos.
Los datos más relevantes obtenidos en el cantón Pichincha se toma cuidado debido a que 19 de las muestras salieron positivas (70.3\%) con RB de las cuales 12 al ser analizadas con PCR fueron negativas (44.4\%), teniendo una correlación de $52.6 \%$, lo que indica una alta incidencia de la enfermedad. Mientras tanto que de las 8 muestras negativas con RB, 2 fueron positivas con PCR dando una correlación entre negativos del 75\%.

La comparación de los resultados de la PCR y la serología en muestras de humanos permite concluir que en las condiciones ensayadas de la PCR podría emplearse como instrumento de diagnóstico adicional y rápido para a aquellas situaciones dudosas.

\section{Literatura Citada}

Baily, G. C., J. B. Kraahn, S. Drasar and N. Stokeer. 1992. Deteccion of Brucella melitensis and Brucella abortus by DNA amplification. J. Trop. Med. Hyg. 95: 271-275

Gotuzzo, E., C. Carrillo, C. Seas, O. Alvarez. 1989. Epidemiological and clinical features of brucelosis in family groups. Enf. Infcc. Microbiol. Clin. 7(10): 519-524.

Kaye, D., R. G. Petersdorf. 1989. Brucelosis. In Braunwald, E., K. J. 1sselbacker, R. G. Petersdorf, J. D. Wilson, J. B. Martin, A. S. Fanci, eds. Harrison's: Principios de Medicina Interna. Undécima edición española: 751-754.

Leal-Klevezas, D. S., I. O. Martínez-Vásquez., A. López-Merino. 1995. Single step PCR for the detection of Brucella spp. From blood and milk of infected animals. J. Clin. Microbiol. 33: 3087-3090.

Martín, S., L. Guinea, P. Carreño, R. Visado, S. Garcia, T. Calvo, D. Reverte. 1992. El diagnóstico de la brucelosis en un área endémica. Valoración de las pruebas diagnósticas habituales. Med. Clín. (Barc); 98: 481-487.

Morata, P., I. M. Queipo-Ortuño, M. J. Reguera. 1999. Posttreatment Follow-Up of Brucellosis by PCR Assay. J. Clin. Microbiol. 37:12 4163-4166.

Morata, P., I. Queipo-Ortuño, M. Reguera, F. Miralles, J. López González, D. Colmenero. 2001a. Diagnostic Yield of a PCR Assay in Focal Complications of Brucellosis. J. Clin. Microbiol. 39:10 3743-3746.

Morata, P., I. M. Queipo-Ortuño, D. J. Colmenero. 2001b. PCR Assay for Dignosis of Human Brucellosis. J. Clin. Microbiol. P. 1654 - 1655.

Rabab, A., Al-Attas, Mohammad Al-Khalifa, Abdul Rahman Al-Qurashi, Mohammad Badawy, Nafisa Al-Gualy. 2000. Evaluation of PCR, culture and serology for the diagnosis of acute human brucellosis. Ann. Saudi. Med. 20(3-4):224-228.

Ciencia y Tecnología. 2010. 3(1): 27-32 
Romero, C., C. Gamazo, M. Pardo, Y. López-Goñi. 1995a. Specific detection of Brucella DNA by PCR. J. Clin. Microbiol. 33:615-617.

Romero, C., M. Pardo, J. Grillo, R. Díaz, M. Blasco, I. López-Goñi. 1995b. Evaluation of PCR and Indirect Enzyme-Linked Immunosorbent Assay on Milk Samples for Diagnosis of Brucellosis in Dairy Cattle. J. Clin. Microbiol. 33:12 31983200.

Romero, C., I. López-Goñi. 1999. Improved Method for purification of bacterial DNA from Bovine Milk for detection of Brucella spp. by PCR. A and Env. Microbiol. 65 (8): p. 373-3737.
Salmerón, I., M. Rodríguez-Zapata, O. Salmerón, L. Manzano, S. Vaquer, M. Álvarez-Mon. 1992. Impaired activity of natural killer cells in patients with active brucellosis. Clin. Infect. Dis. 15: 764770 . 